\title{
The Evidence Debate for Behavioural Interventions for Autism
}

\author{
Brian Fennell (Corresponding Author) \\ School of Education, Queen's University Belfast \\ 69 University Street, Belfast BT7 1HL, Northern Ireland, UK \\ Tel: 44-606-694-4411 E-mail: bfennell@icloud.com
}

\begin{abstract}
Karola Dillenburger
School of Education, Queen's University Belfast

69 University Street, Belfast BT7 1HL, Northern Ireland, UK

Tel: 44-289-097-5985Ｅ-mail: k.dillenburger@qub.ac.uk
\end{abstract}

Received: January 25, 2014 Accepted: March 13, $2014 \quad$ Published: April 24, 2014

doi:10.5296/ire.v2i2.4989 URL: http://dx.doi.org/10.5296/ire.v2i2.4989

\begin{abstract}
For more than fifty years evidence has been accrued regarding the efficacy of applied behaviour analysis-based interventions for individuals with autism spectrum disorders. Despite this history of empirical evidence, some researchers and ASD experts still are reluctant to accept behavioral interventions as best practice for ASD. In this paper, we consider both random control trials and single subject experimental designs as forms of evidenced-based practice (EBP). Specific application of these methods to ASD research is considered. In an effort to provide scientifically based evidence for interventions for ASD, EBP standards have been debated without a consensus being achieved. Service users of ASD interventions need access to sound empirical evidence to choose appropriate programmes for those they care for with ASD rather than putting their hopes in therapies backed by pseudoscience and celebrity endorsements.
\end{abstract}

Keywords: Autism Spectrum Disorders, Applied Behaviour Analysis, Evidence Based Practice, Single Subject Experimental Design 


\section{Introduction}

Applied Behaviour Analysis (ABA), i.e., the application of the science of behaviour analysis to real life settings to enhance socially relevant behaviours, was first defined by Baer, Wolf, and Risely in 1968 and since then has been documented through peer reviewed journals (e.g. Journal of Applied Behavior Analysis) and other scholarly works (Dixon, Vogel, \& Tarbox, 2012; Grant \& Evans, 1994). As a product of the early experimental work of behaviour analysts such as B. F. Skinner (1938), applied behaviour analysis grew a rich history of research (Cooper, Heron, \& Heward, 2007). It is in recent years, however, that ABA has become a prominent focal point for medical as well as educational debate with regard to applications to support individuals with autism spectrum disorders (Shyman, 2012).

Rising rates of ASD have thrust the issue of effective education for these students to the fore in many global jurisdictions (Kearns \& Shevlin, 2006; National Council for Special Education, 2013; Watson, 2009). The behaviour analytic literature has been clear since its inception that ABA is the application of the science of behaviour analysis (Cooper et al., 2007) and as such the most effective basis for developing scientific methods of changing behaviours that are socially relevant, i.e. addressing behaviours that prevent individuals from being included fully in society (Kerr, Mulhern, \& McDowell, 2000). While the science predates Skinner (1938) and Kanner (1943), those not familiar with its history often confused it as a method of teaching those with autism spectrum disorders (ASD) rather than the application of scientific principles of behaviour that affect all learners (Dillenburger \& Keenan, 2009).

The problem that lies at the root of this erroneous categorization of ABA is that it is wrongly viewed as one intervention method for ASD. In fact, this is a characteristic category mistake (Dillenburger, 2011), when an overarching category is viewed as part of a lower level category. In this case, ABA (the overarching category) is set side-by-side with specific procedures that are based in ABA, such as picture exchange communication system (PECS) or discrete trial teaching (DTT). This kind of miscategorization of ABA has become one of the main the debates in the autism intervention 'wars' (Maurice, 2003).

\section{Brief History of ABA-Based Interventions in ASD}

Behavioural principles have been discovered and explored in the laboratory since the late $19^{\text {th }}$ and early $20^{\text {th }}$ century before being applied to human behaviour in naturall contexts (Dixon et al., 2012). Many early behavioural interventions were applied to research subjects who were in State care due to a diagnosis of mental illness or intellectual disabilities. Fuller's (1949) work is widely regarded as the first deliberate application of behavioural principles to humans. He used positive reinforcement (e.g. a sweetened milk solution) to increase the right arm movements of a previously non-responsive patient and therefore showed that even this patient could learn a new behaviour. Ayllon and Michael (1959) taught staff nurses to use reinforcement techniques to improve appropriate behaviours in patients in a psychiatric hospital and reported impressive results. Some research during this early period was also concerned with the population diagnosed with autism, for example Ferster (1961) offers a very early behaviour analysis of autism with a focus on functional analysis, and Ferster and DeMyer (1961) used an automated sweet dispenser to reinforce the lever pressing behaviour 
of two subjects with autism to show that learning/teaching is possible even for low-functioning individuals with autism.

Although predated by this earlier research, Lovaas et al. (1987) received most of the attention for their application of one specific behaviour analysis-based method, i.e., discrete trial teaching, to young people with ASD. The study showed the effectiveness of early intensive behavioural intervention with young children on the autism spectrum. A follow-up report (McEachin, Smith, \& Lovaas, 1993) indicated the long-term maintenance of the gains when these children were teenagers and adults. For many not familiar with the scientific discipline of behaviour analysis, Lovaas' name became synonymous with ABA interventions for ASD (Jordan, Jones, \& Murray, 1998).

The Lovaas et al.'s (1987/ 1993) studies have often been misinterpreted as an evaluation of a complete intervention system designed for application for those with ASD (Jones, 2002) with little or no recognition of their basis in applied behaviour analysis. This kind of misinformation has led to a public perception that Lovaas Therapy or Lovaas Programme is the same as ABA (Dillenburger \& Keenan, 2009).

ABA based procedures have been developed for many other populations. For example, Iwata and colleagues (1982) conducted functional analysis on the self-injurious behaviours of participants with intellectual disabilities (ID), while Carr and Durand (1985) reinforced appropriate communication skills to reduce challenging behaviours of a group of students with ID in a school setting. In the past, many studies that identify participants as having intellectual disabilities include individuals with ASD among the subjects (Matson, Bamburg, Cherry, \& Paclawskyj, 1999). A highly successful programme introducing healthy eating to early school-aged children has been adopted in several countries (e.g. UK, Ireland, and several US states) in an effort to combat growing childhood obesity rates (Horne et al., 2008). The Food Dudes programme uses behavioural techniques, including positive reinforcement and peer modeling, to improve dietary behaviours in children with the aim to improve lifelong health outcomes. This programme is implemented successfully across whole-school communities including typically developing individuals, children with learning disabilities, and others with ASD.

Because of the recent increased focus on ASD, and in order to make replication studies possible, more detailed descriptions of participants with ASD have been introduced. Currently, research reports typically include information regarding ASD diagnostic criteria used, subgroup membership and functional abilities (e.g. IQ level, adaptive behavior scores, receptive/ expressive language; O’Reilly et al., 2010).

\subsection{Home-Based ABA and Parent Advocacy}

In the early days most applications of ABA with people with autism were conducted through home-based programmes with parents as active partners (Keenan, Kerr, \& Dillenburger, 2000). In the absence of state recognition of the benefits of behavioural interventions, home-based ABA programmes are still predominant in Ireland, both north and south of the border (Dillenburger, 2011). Reports of successful ABA home interventions implemented by parents 
are plentiful (Dillenburger, Keenan, Gallagher, \& McElhinney, 2004). Catherine Maurice (1994), the mother of two children diagnosed with severe ASD, recounts the intensive behavioural intervention carried out in the home that resulted in her children's recovery from autism and inclusion in mainstream schooling without additional supports.

In fact, parental advocacy, defined as 'public support for or recommendation of a particular cause or policy' (Oxford Dictionary, 2005), has become a major contributor to increased autism awareness. Through organized support groups and, increasingly, social media (e.g. Facebook, Twitter) parental advocacy has become instrumental at the grass roots for raising autism awareness, demanding evidence-based effective interventions, and legal rights (Maurice, 1994).

Parent advocacy for behaviour interventions has been essential in the growth of ABA-based provision of services, against the backdrop of reluctance of governments and school systems to provide ABA-based services for children with ASD in the US (Mulick \& Butter, 2002), Northern Ireland (Keenan et al., 2000) and the Republic of Ireland (O'Sullivan, 2010). The success of parent advocacy to bring about the recognition of ABA as an empirically supported educational intervention for autism is nowhere more evident than in the US.

\section{US Support for ABA}

Whereas the recent legislation in most States of the US has dramatically improved the funding for behavioural interventions by requiring insurance carriers to provide coverage of ABA-based services (Autism Speaks, 2013), there is a long history of support in the US for ABA-based methods. Official US government support is evident in the report of the US Surgeon General that states:

Thirty years of research demonstrate the efficacy of applied behavioral methods in reducing inappropriate behavior and in increasing communication, learning, and appropriate social behavior (US Surgeon General, 1999, p. 164).

This endorsement expands on earlier federal legislation (United States Congress, 1997), which requires the use of functional behavioural assessment and positive behaviour support in publically funded education; methodologies with their foundations firmly established in the science of behaviour.

In addition to the support of the US Federal Government and individuals States through insurance reform laws, other initiatives also add to the endorsement of behavioural interventions for ASD. The State of Maine convened a task force to evaluate the educational interventions for ASD as a means of determining appropriate State policy in the area (Maine Administrators of Service for Children with Disabilities, 2000). The task force, citing some of the key features of ABA such as the use of observable goals, reliable data collection, and programme evaluation based on data evidence, declared behavioral interventions 'substantiated as effective based on the scope and quality of research' (Maine Administrators of Service for Children with Disabilities, 2000).

The New York State Department of Health (1999) also recommended interventions for ASD 
should be based on ABA due to sufficient supporting research evidence. An international expert group, funded through US Government autism research grants, also concluded that behavioural programmes were supported by evidence (Maglione, Gans, Das, Timbie, \& Kasari, 2012). Although the researchers made the category error of using the term Lovaas/ABA, the interventions that were given the highest rating were ABA -based interventions (e.g.. picture exchange communication system; Early Start Denver Model). These positive findings were despite the exclusion of all single subject research evidence from this review. The Kennedy Krieger Institute of Maryland (USA) and Autism Speaks (US $\&$ Canada) are among the many agencies that promote the use of ABA-based interventions for the people with ASD whom they support.

\section{Evidenced Based Practice in ASD}

The term 'evidence based practice' (EBP) appears in much of the recent literature on scientifically based interventions for ASD (Reichow, Volkmar, \& Cicchetti, 2008). In fact, US legislation No Child Left Behind (No Child Left Behind Act, 2001) defines scientifically based research as:

Research that involves the application of rigorous, systematic, and objective procedures to obtain reliable and valid knowledge relevant to education activities and programs (Title IX, Sec. 9101, 37).

While the research base of behaviour analytic interventions for ASD has been widely recognized, including by government sources, this Act paradoxically states a preference for randomized controlled trials, rather than single-system research designs. The US Department of Education has since provided supporting materials indicating effective practices for use by educators (U.S. Department of Education, 2014) but these do not included ASD interventions (Mesibov \& Shea, 2011).

Comprehensive systematic literature reviews of ABA-based interventions for ASD, that include all relevant research methodologies, e.g. single system designs, meta-analyses, and systematic reviews, have been generally supportive. The National Standards Project (2009) gave its highest rating of 'established' to behavioural interventions and noted that all but one of the methods in this category were derived from the science of behaviour analysis. However, reviews that are solely based on RCTs commonly report insufficient scientific evidence for all ASD interventions, including those based on ABA (National Research Council, 2001).

While it may have been expected that these reviews would simply document the scientific validity of interventions for ASD, the contradictory results have muddied the waters (Matson, Adams, Williams, \& Rieske, 2013) rather than clarify substantiated practices. The debate among researchers commonly focuses on the experimental methodologies considered as scientific evidence (Shyman, 2012) rather than the applied effectiveness of the intervention.

\subsection{Methods of Experimental Research in ASD}

The literature of educational interventions for ASD offers two distinct experimental designs: Random controlled trials (RCT) and Single System Experimental Design (SSED). Random 
controlled trials utilize a group comparison approach that stems from the medical sciences (e. g. drug trials). In an RCT, treatment effects are compared between groups, with a non-treatment group serving as a control for the treatment group (Keenan \& Dillenburger, 2011). The hallmarks of RCT include multiple groups of test subjects and random assignment of subjects to groups. One group receives the treatment intervention (i.e. experimental group) while the other group does not (i.e. the control group). Data are analyzed to determine the difference between these groups post-intervention (Green, 2008).

On the other hand, behaviour analysis research utilizes the inductive approach used in other natural sciences where the individual serves as his/her own control, i.e., single subject experimental designs (SSED). SSEDs have been employed to study the effects of treatment protocols on individuals (e.g. Carr \& Durand, 1985). In SSEDs, the target behaviour is measured prior to the application of the experimental condition and this measure is referred to as the baseline level of the behaviour. Once a stable baseline is established, treatment is commenced and additional procedures (e.g. ABAB Reversal which alternates between baseline (A) and treatment (B) several times or multiple baseline designs) are undertaken to establish experimental control; (Keenan \& Dillenburger, 2012). Researchers continue to develop improved statistical analyses of SSED for improved comparison with traditional RTC experiments. For example, researchers have recently formulated a standard mean difference statistic that allows direct comparison with the standard mean difference statistic for intergroup comparisons (Shadish, Hedges, \& Pustejovsky, 2014).

While the unit of analysis for SSED is the behaviour of an individual system, Sackett (2011) recommends treating them as $n=1$ RCTs and as such researchers can include multiple participants in the experiment. An example of this methodology is the multiple baselines across participants design. This design requires several subjects with similar target behaviours receiving the same intervention (Horner et al., 2005). Carr and Durand (1985), for example, collected data for four individuals. Baseline measures were taken for each subject, intervention implemented, and outcome measures were then recorded. Data for each subject are then visually analyzed through graphs for treatment effect (Horner et al., 2005). This scenario can in fact be viewed as four separate replications of the experiment that allows the researcher to verify their findings for an individual case. Moeyaert and colleagues (2014) recently advanced methodologies for comparisons of effect size (i.e. degree of effectiveness) across individual cases in SSED interventions. This allows researchers to estimate effect size for individual cases and predict generalization of treatment effect to future cases (Moeyaert et al., 2014).

The merits of each methodology are considered in the debate on EBP for autism education. Intervention reviews such as that conducted by the National Research Council (2001) contend that only RCTs meet the full rigors of scientific evidence and, therefore, are the only methodology that is valid as evidence of best practice methods in educating students with ASD. The What Works Clearing House (U.S. Department of Education, 2014) as well as behaviour analysts, such as Green (2008) refute this exclusive position and argue in support of the inclusion of SSED as scientific standard for evaluation and further declare that SSED methodology is the appropriate methods for the evaluation of individually-tailored 
interventions, such as those based in ABA. However, recent proposals suggest those engaged in SSED, and particularly ABA researchers, begin to add statistical analyses (e.g. those presented by (Moeyaert et al., 2014; Shadish et al., 2014) to the standard procedures as a means to increase inclusion in meta-analyses and a possible increase in acceptance of ABA methodology (Fisher \& Lerman, 2014).

The relative strength of RCT is in the large number of experimental subjects involved in each study (Keenan \& Dillenburger, 2011). However, Johnston and Pennypacker (1993) contend that the individual focus of SSED is advantageous and particularly significant in the field of ASD due to the unique characteristics of each individual diagnosed with autism and the functionally based interventions. Another critique of RCTs is that when results are reported as average outcome across the group treatment effect for individual behaviours/participants is absorbed into this average (Dounavi \& Dillenburger, 2013). The statisticall means are of little value to the population with ASD who present with a wide variety of excesses and deficits in multiple domains (Green, 2008; Johnston \& Pennypacker, 1993). Decision-makers are more likely to be able to match the attributes of their child and targeted outcomes with those of single subject research involving children with similar attributes and goals (Green, 2008).

In an effort to develop a set of criteria for evaluation of the intervention results, Reichow and colleagues (2008) developed a set of rubrics that equate 8 SSED studies with one group study (e.g. RCT). Odom and colleagues (2010) proposed a ratio of 5 SSED studies to two RCT experiments.

Like other natural sciences behavior analysis takes the individualized inductive approach and has a long, rich history of evidencing effectiveness of interventions with many populations, including people with ASD (Keenan \& Dillenburger, 2011). ASD, a disability with highly diverse behavioural deficits and abilities across individuals, is particularly suited for SSED research as it is an inductive methodology that maintains individual subject data (Mesibov \& Shea, 2011).

\subsection{ABA-Based Interventions Compared to Other Medical and/or Educational Interventions}

While the campaign to assess the scientific basis of interventions has gained momentum since the No Child Left Behind (No Child Left Behind Act, 2001) in the US, EBP has not become part of intervention protocol on a global scale. Although educational intervention for ASD has been a focus in Ireland (Parsons et al., 2009), Northern Ireland (Maginnis, 2008), and Scotland (Dunlop et al., 2009), outside of the US the call for empirically based methods in ASD treatment and education has been noticeably absent (Dillenburger, 2011). The more accurate outline of ABA as the scientific basis for interventions and the subsequent full endorsement of behaviourally/functional assessment based interventions in the new guidelines from the UK National Institute of Clinical Excellence (NICE, 2013), Autism: The management and support of children and young people on the autism spectrum, offer a glimmer of hope that this state of affairs is about to change.

Despite the lack of an operational definition (Dillenburger, 2011), a single approach to intervention, i.e., eclecticism, still is supported widely as approach to ASD by prominent 
academics (Cumine, Leach, \& Stevenson, 2000; Powell \& Jordan, 1997) and the governments of the Republic of Ireland (The Task Force on Autism, 2001), Northern Ireland (Task Group on Autism, 2002) and Scotland (Dunlop et al., 2009). Jordan (2004) is a prominent example of the mis-conceptualisation of eclecticism as the only way to respond to individual or situational needs:

The strength of the eclectic approach is not just that it can combine the 'best' features of other interventions but that it can be responsive to the individual and to the situation. All interventions have several aspects or parts, some of which may be very different from one another (p. 5).

As the term 'spectrum' indicates, ASD is a heterogeneous condition and no self-respecting clinician could possibly conceive of using one specific procedure to address all the issues for all individual with ASD all of the time. Clearly, clinical decision-making should be based on evidence-based practice as the preferred approach based on single-system evaluations and research methodologies that are utilized, e.g., in applied behaviour analytic interventions to ensure that treatment decisions are individually tailored based on evidential data of effectiveness.

In fact, the problems with definition of eclecticism become apparent in attempts to evaluate its effectiveness. In order to undertake comparative research, investigators have to develop specific packages of eclectic interventions for their studies. For example, Eikeseth and colleagues (2002) conducted a RCT between subjects receiving an intensive behavioural programme and an eclectic approach. The eclectic programme offered elements of TEACCH, discrete trial training (DTT), sensory-motor therapy, and other methods from the teacher's personal experience. A multidisciplinary team determined the programme. Both groups of subjects received one-to-one instruction for 28 hours per week over the course of one year. The behaviour-analytic treatment group showed significant gains in IQ (i.e. an average of 17 points), language, and adaptive behaviours when compared to the eclectic group (i.e. an average 4 point gain in IQ). Additionally, the ABA-based treatment group in this study showed fewer challenging behaviours and social difficulties (Eikeseth, Smith, Jahr, \& Eldevik, 2007).

In a similar study (Howard, Sparkman, Cohen, Green, \& Stanislaw, 2005), the eclectic programme included methods commonly used in autism specific settings (i.e. PECS, TEACCH, and DTT) along with educational methods used in standard pre-school practice (e.g. circle time and music). The staff to student ratio was 1:1 or 1:2 for each of three research groups: the eclectic group, the ABA-based group, and the general curriculum group in special needs pre-schools (i.e. not autism specific). Howard et al. (2005) reported significant advantages for the ABA-based interventions group in the areas of cognitive, non-verbal, and communication measures in comparison to both other groups.

The proponents of the eclectic methodology (e.g. Jordan, 2004) do not offer guidance as to what interventions to include in this approach. In fact, often multiple interventions or part-interventions are combined or employed concurrently with little planning or measurements of effects (Matson et al., 2013). As there is no definition or model of an 
eclectic approach to ASD education, it is impossible to use scientific methods to determine the efficaciousness of eclecticism per se. While individual parts of an eclectic model may or may not have empirical support, the combined synergetic effects of these parts is not amenable to scientific scrutiny as each new permutation would require a novel set of trials (Dillenburger, 2011).

While eclecticism is advocated as an inclusive approach to the education of individuals with ASD, the failure of its proponents to discriminate among interventions, in terms of efficacy, is a major flaw. The potential to include ineffective, unsubstantiated interventions is challenging (e.g. facilitated communication, auditory integration training: Leaf, Taubman, \& McEachin, 2008). This may also encourage a 'chop and change', or 'pick and mix' mentality to interventions where elements may be added or dropped without allowing for effects to be evaluated adequately (Matson et al., 2013).

Teacher training and, more generally, staff training in the interventions strategies that may be included in an eclectic approach is also problematic. Mastery of all of the knowledge and skills needed to apply multiple therapies with acceptable programme fidelity is virtually impossible (Dillenburger, 2011). Training of teachers in some of the complex intervention technologies has proved to be difficult and ineffective, especially when provided in short CPD courses (Scott, Liaupsin, Nelson, \& McIntyre, 2005; Van Acker, Borenson, Gable, \& Potterton, 2005). Considering this evidence, it is unrealistic to expect any individual teacher to be knowledgeable in the theoretical bases and methodologies of several complex technologies with acceptable efficacy (Dillenburger, 2011).

Eclectic approaches to ASD education must be subject to the same empirical testing if these are to be included in the literature of EBP. There is no large scale RCTs at present that support eclectic interventions used in the education of children with ASD. Untested elements combined in this mixed approach can confound the empirical evidence for the overall programme as each component will need to be evaluated in a component analysis for it contribution to the overall outcome effect and even if this were possible, the synergetic effect of the overall programme would need to be established. Given that it is impossible to link positive outcomes with any specific component part of the overall eclectic programme (Leaf et al., 2008), it may even be the case that elements of an eclectic package are in conflict with another and cancel out their respective effects (Dillenburger, 2011). Inclusion of all the empirical data, derived from both RTC and SSED methods, allows for a very clear message to parents and educators. The scientific support for ABA-based interventions is clearly superior to that for other methods (Dillenburger, 2011). Confusion regarding the EBP mandate in the US is the direct result of the application of inconsistent criteria (Odom et al., 2010) by researchers assembling data in support of interventions for ASD. This confusion is passed on to parents and educators who are presented with a distorted picture of the effectiveness of interventions for ASD (Matson et al., 2013).

\section{Conclusion}

Matson and colleagues (2013) have found that parents frequently rely on word of mouth from other parents, celebrity endorsements, and, at times, inaccurate information provided by 
professionals at some of the national autism organizations rather than the EBP evidence available. Although parents are making an effort to educate themselves about the best available therapies for ASD, the Internet and social media present methods along with expert endorsements that are not supported by empirical evidence (Matson et al., 2013).

While some researchers argue that the relative disregard for the evidential basis by consumers (i.e. parents, teachers, and school administrators) is an indication of the social preference of eclectic and non-EBP methods (Callahan, Shukla-Mehta, Magee, \& Wie, 2010), others regard the problem as one of professional training and standards within the EBP framework (Odom et al., 2010; Reichow et al., 2008). In fact, the continued resistance of some in the research community to accept the empirical data, including SSED data, has created a situation where well-meaning districts, teachers, and parents are withholding potentially beneficial treatment for people with ASD. Consumers need access to EBP information rather than a continued reliance on erroneous misinformation or celebrity endorsements but this might require a sea change for the scientific community. Direct outreach, through mass medila and social media outlets, would help put research information in the hands of those who need it.

\section{References}

Autism Speaks. (2013). Fiscal impact of autism insurance reform.

Ayllon, T., \& Michael, J. (1959). The psychiatric nurse as a behavioral engineer. Journal of the Experimental Analysis of Behavior, 2(4), 323-334. http://dx.doi.org/10.1901/jeab.1959.2-323

Callahan, K., Shukla-Mehta, S., Magee, S., \& Wie, M. (2010). ABA versus TEACCH: The case for defining and validating comprehensive treatment models in autism. Journal of $\begin{array}{llll}\text { Autism and Developmental } & \text { Disorders, } & \text { 40, }\end{array}$ http://dx.doi.org/10.1007/s10803-009-0834-0

Carr, E. G., \& Durand, V. M. (1985). Reducing behavior problems through functional communication training. Journal of Applied Behavior Analysis, 18, 111-126. http://dx.doi.org/10.1901/jaba.1985.18-111

Cooper, J. O., Heron, T. E., \& Heward, W. L. (2007). Applied behavior analysis (Second ed.). Upper Saddle River, New Jersey: Pearson Education, Inc.

Cumine, V., Leach, J., \& Stevenson, G. (2000). Autism in the early years: A practical guide. London: David Fulton Publishers.

Dillenburger, K. (2011). The emperor's new clothes: Electicism in autism treatment. Research in Autism Spectrum Disorders, 5(3), 1119-1128. http://dx.doi.org/10.1016/j.rasd.2010.12.008

Dillenburger, K., \& Keenan, M. (2009). None of the A's in ABA stand for autism: Dispelling the myths. Journal of Intellectual \& Developmental Disabilities, 34(2), 193-195. http://dx.doi.org/10.1080/13668250902845244 
Dillenburger, K., Keenan, M., Gallagher, S., \& McElhinney, M. (2004). Parent education and home-based behaviour analytic intervention: An examination of parents' perceptions of outcome. Journal of Intellectual and Developmental Disability, 29(2), 119-130. http://dx.doi.org/10.1080/13668250410001709476

Dixon, D. R., Vogel, T., \& Tarbox, J. (2012). A brief history of functional analysis and applied behavior analysis. In J. L. Matson (Ed.), Functional assessment for challenging behaviors (1st ed., pp. 3-24). Tarzana, CA USA: Springer Science and Business Media. http://dx.doi.org/10.1007/978-1-4614-3037-7_2

Dunlop, A., Tait, C., Leask, A., Glashan, L., Robinson, A., \& Marwick, H. (2009). The autism toolbox. The Scottish Government, Edinburgh.

Eikeseth, S., Smith, T., Jahr, E., \& Eldevik, S. (2002). Intensive behavioral treatment at school for 4-to 7-year-old children with autism: A 1-year comparison controlled study. Behavior Modification, 26(1), 49-68. http://dx.doi.org/10.1177/0145445502026001004

Eikeseth, S., Smith, T., Jahr, E., \& Eldevik, S. (2007). Outcome for children with autism who began intensive behavioral treatment between ages 4 and 7 a comparison controlled study. Behavior Modification, 31(3), 264-278. http://dx.doi.org/10.1177/0145445506291396

Ferster, C., \& DeMyer, M. K. (1961). The development of performances in autistic children in an automatically controlled environment. Journal of Chronic Diseases, 13(4), 312-345. http://dx.doi.org/10.1016/0021-9681(61)90059-5

Fisher, W. W., \& Lerman, D. C. (2014). It has been said that,"There are three degrees of falsehoods: Lies, damn lies, and statistics". Journal of School Psychology, 52(2), 243-248. http://dx.doi.org/10.1016/j.jsp.2014.01.001

Fuller, P. R. (1949). Operant conditioning of a vegetative human organism. The American Journal of Psychology, 62(4), 587-590. http://dx.doi.org/10.2307/1418565

Grant, L., \& Evans, A. (1994). Principles of behavior analysis (First ed.). New York: Harper Collins.

Green, G. (2008). Single-case research methods for evaluating treatments for autism spectrum disorders. In S. Luce, D. Mandell, C. Mazefsky \& W. Seibert (Eds.), Autism in Pennsylvania: What lies ahead? (pp. 69-81) The Pennsylvania House of Representatives, Pennsylvania USA.

Horne, P., Hardman, C., Lowe, C., Tapper, K., Le Noury, J., Madden, P., . . . Doody, M. (2008). Increasing parental provision and children's consumption of lunchbox fruit and vegetables in Ireland: The food dudes intervention. European Journal of Clinical Nutrition, 63(5), 613-618. http://dx.doi.org/10.1038/ejen.2008.34

Horner, R. H., Carr, E. G., Halle, J., Mcgee, G., Odom, S., \& Wolery, M. (2005). The use of single-subject research to identify evidence-based practice in special education. Exceptional Children, 71(2), 165-179. http://dx.doi.org/10.1177/001440290507100203 


\section{Macrothink}

International Research in Education

ISSN 2327-5499

2014, Vol. 2, No. 2

Howard, J. S., Sparkman, C. R., Cohen, H. G., Green, G., \& Stanislaw, H. (2005). A comparison of intensive behavior analytic and eclectic treatments for young children with autism. Research in Developmental Disabilities, 26(4), 359-383. http://dx.doi.org/10.1016/j.ridd.2004.09.005

Iwata, B. A., Dorsey, M. F., Slifer, K. J., Bauman, K. E., \& Richman, G. S. (1994). Toward a functional analysis of self-injury. Journal of Applied Behavior Analysis, 27(2), 197-209. http://dx.doi.org/10.1901/jaba.1994.27-197

Johnston, J. M., \& Pennypacker, H. S. (1993). Strategies and tactics of human behavioral research Routledge.

Jones, G. (2002). Educational provision for children with autism and Asperger syndrome: Meeting their needs (First ed.). London: David Fulton Publishers.

Jordan, R. (2004). Meeting the needs of children with autistic spectrum disorders in the early years. Australian Journal of Early Childhood, 29(3), 1-7.

Jordan, R., Jones, G., \& Murray, D. (1998). Educational interventions for children with autism: A literature review of recent and current research. (Research Report No.77). Norwich, UK: Department for Education and Employment, UK.

Kanner, L. (1943). Autistic disturbance of affective contact. Nervous Child, 2, 217-250.

Kearns, H., \& Shevlin, M. (2006). Initial teacher preparation for special educational needs: Policy and practice in the north and south of Ireland. Teacher Development, 10(1), 25-42. http://dx.doi.org/10.1080/13664530600587287

Keenan, M., \& Dillenburger, K. (2011). When all you have is a hammer...:RTCs and hegemony in science. Research in Autism Spectrum Disorders, 5, 1-13. http://dx.doi.org/10.1016/j.rasd.2010.02.003

Keenan, M., \& Dillenburger, K. (2012). Behavior analysis: A primer (Electronic Book ed.) Celtic Fringe Production.

Keenan, M., Kerr, K. P., \& Dillenburger, K. (2000). Parents' education as autism therapists: Applied behaviour analysis in context. Jessica Kingsley Publishers.

Kerr, K. P., Mulhern, F., \& McDowell, C. (2000). Applied behaviour analysis: It works, it's positive; now what's the problem? Early Childhood Development and Care, 163, 125-131. http://dx.doi.org/10.1080/0300443001630109

Leaf, R. B., Taubman, M. T., \& McEachin, J. (2008). Sense and nonsense in the behavioral treatment of autism: It has to be said. New York: DRL Books.

Lovaas, O. I. (1987). Behavioral treatment and normal educational and intellectual functioning in young autistic children. Journal of Consulting and Clinical Psychology, 55(1), 3-9. http://dx.doi.org/10.1037/0022-006X.55.1.3 


\section{Macrothink}

International Research in Education

ISSN 2327-5499

2014, Vol. 2, No. 2

Maginnis, K. (2008). Independent review of autism services. Belfast, Northern Ireland: Department of Health.

Maglione, M. A., Gans, D., Das, L., Timbie, J., \& Kasari, C. (2012). Nonmedical interventions for children with ASD: Recommended guidelines and further research needs. Pediatrics, 130(2) 169-178. http://dx.doi.org/10.1542/peds.2012-0900O

Maine Administrators of Service for Children with Disabilities. (2000). Report of the MADSEC Autism Task Force.

Matson, J. L., Adams, H. L., Williams, L. W., \& Rieske, R. D. (2013). Why are there so many unsubstantiated treatments in autism? Research in Autism Spectrum Disorders, 7(3), 466-474. http://dx.doi.org/10.1016/j.rasd.2012.11.006

Matson, J. L., Bamburg, J. W., Cherry, K. E., \& Paclawskyj, T. R. (1999). A validity study on the questions about behavioral function (QABF) scale: Predicting treatment success for self-injury, aggression, and stereotypies. Research in Developmental Disabilities, 20(2), 163-175. http://dx.doi.org/10.1016/S0891-4222(98)00039-0

Maurice, C. (1994). Let me hear your voice: A family's triumph over autism. Random House Digital, Inc.

Maurice, C. (2003). The autism wars. Exceptional Children: An Introduction to Special Education, 490-492.

McEachin, J. J., Smith, T., \& Lovaas, O. I. (1993). Long-term outcome for children with autism who received early intensive behavioral treatment. American Journal of Mental Retardation, 97, 359-372.

Mesibov, G. B., \& Shea, V. (2011). Evidence-based practices and autism. Autism, 15(1), 114-133. http://dx.doi.org/10.1177/1362361309348070

Moeyaert, M., Ferron, J. M., Beretvas, S. N., \& Van den Noortgate, W. (2014). From a single-level analysis to a multilevel analysis of single-case experimental designs. Journal of School Psychology, 52(2), 191-211. http://dx.doi.org/10.1016/j.jsp.2013.11.003

Mulick, J., \& Butter, E. M. (2002). Educational advocacy for children with autism. Behavioral Interventions, 17(2), 57-74. http://dx.doi.org/10.1002/bin.106

National Council for Special Education. (2013). Supporting students with special educational needs in schools. (Policy Advice Paper No.4). Trim, Co. Meath, Ireland: National Council for Special Education (NCSE).

National Research Council. (2001). Educating children with autism. Washington, D.C.: The National Academies Press.

National Standards Project. (2009). National standards project report. Randolph, Massachusetts: National Autism Center. 
New York State Department of Health. (1999). Clinical practice guidelines: Report of the recommendations. Autism/ pervasive developmental disorders assessment and intervention for young children (age 0-3 years). (No. 4215). New York.

No Child Left Behind. Public law 107-110, (2001).

O’Reilly, M., Rispoli, M., Davis, T., Machalicek, W., Lang, R., Sigafoos, J., ... Didden, R. (2010). Functional analysis of challenging behavior in children with autism spectrum disorders: A summary of 10 cases. Research in Autism Spectrum Disorders, 4(1), 1-10. http://dx.doi.org/10.1016/j.rasd.2009.07.001

Odom, S. L., Collet-Klingenberg, L., Rogers, S. J., \& Hatton, D. D. (2010). Evidence-based practices in interventions for children and youth with autism spectrum disorders. Preventing School Failure: Alternative Education for Children and Youth, 54(4), 275-282. http://dx.doi.org/10.1080/10459881003785506

O'Sullivan, C. (2010, July 15, 2010). Proposals will end the teaching of ABA, parents claim. IrishExaminer

Oxford Dictionary. (2005). In Soanes C., Hawker S. and Elliott J. (Eds.), Pocket Oxford English Dictionary (Tenth ed.). Oxford: Oxford University Press.

Parsons, S., Guldberg, K., MacLeod, A., Jones, G., Prunty, A., \& Balfe, T. (2009). International review of the literature of evidence of best practice provision in the education of persons with autism spectrum disorders. Trim, Co. Meath, Ireland: National Council for Special Education.

Powell, S., \& Jordan, R. (1997). Autism and learning: A guide to good practice. Routledge.

Reichow, B., Volkmar, F. R., \& Cicchetti, D. V. (2008). Development of the evaluative method for evaluating and determining evidence-based practices in autism. Journal of Autism and Developmental Disorders, 38(7), 1311-1319. http://dx.doi.org/10.1007/s10803-007-0517-7

Scott, T. M., Liaupsin, C., Nelson, C. M., \& McIntyre, J. (2005). Team-based functional behavior assessment as a proactive public school process: A descriptive analysis of current barriers. Journal of Behavioral Education, 14(1), 57-71. http://dx.doi.org/10.1007/s10864-005-0961-4

Shadish, W. R., Hedges, L. V., \& Pustejovsky, J. E. (2014). Analysis and meta-analysis of single-case designs with a standardized mean difference statistic: A primer and applications. Journal of School Psychology, 52(2), 123-147. http://dx.doi.org/10.1016/j.jsp.2013.11.005

Shyman, E. (2012). Teacher education in autism spectrum disorders: A potential blueprint. Education and Training in Autism and Developmental Disabilities, 47(2), 187.

Skinner, B. F. (1938). The behavior of organisms: An experimental analysis. New York: D. Appleton-Century Co. 


\section{Macrothink}

International Research in Education

ISSN 2327-5499

2014, Vol. 2, No. 2

Task Group on Autism. (2002). The education of children and young people with autism spectrum disorders. Belfast, Northern Ireland: Department of Education, Northern Ireland.

The Task Force on Autism. (2001). Education provision and support of persons with autistic spectrum disorders: The report of the task force on autism (1st ed.). Dublin: Department of Education and Science, Stationary Office.

U.S. Department of Education. (2014). What works clearinghouse. Retrieved January 22, 2014, from http://ies.ed.gov/ncee/wwc/default.aspx

United States Congress. (1997). Individuals with disabilities education act (IDEA). Washington DC: US Congress.

US Surgeon General. (1999). Mental health: A report of the surgeon general. Retrieved 28 January, 2010, from http://www.surgeongeneral.gov/library/mentalhealth/home.html

Van Acker, R., Borenson, L., Gable, R., A., \& Potterton, T. (2005). Are we on the right course? Lessons learned about current FBA/BIP practices in schools. Journal of Behavioral Education, 14(1), 35-56. http://dx.doi.org/10.1007/s10864-005-0960-5

Watson, S. F. (2009). Barriers to inclusive education in Ireland: The case for pupils with a diagnosis of intellectual and/or pervasive developmental disabilities. British Journal of Learning Disabilities, 37, 277-284. http://dx.doi.org/10.1111/j.1468-3156.2009.00583.x

\section{Copyright Disclaimer}

Copyright reserved by the authors.

This article is an open-access article distributed under the terms and conditions of the Creative Commons Attribution license (http://creativecommons.org/licenses/by/3.0/). 